\title{
Instructional Design for EFL Reading at Senior High Schools from the Perspective of Thinking Quality
}

\author{
Yanhong Shao ${ }^{1,2} \&$ Shumin Kang ${ }^{3}$ \\ ${ }^{1}$ Faculty of Education, Qufu Normal University, Qufu, Shandong, China \\ ${ }^{2}$ Jiangsu Xiangshui Senior High School, Yancheng, Jiangsu, China \\ ${ }^{3}$ College of Foreign Languages, Qufu Normal University, Qufu, Shandong, China \\ Correspondence: Shumin Kang, College of Foreign Languages, Qufu Normal University, Qufu, Shandong, \\ 273165, China.
}

Received: October 26, 2021

Accepted: November 22, $2021 \quad$ Online Published: November 26, 2021

doi: $10.5539 /$ elt.v14n12p144

URL: https://doi.org/10.5539/elt.v14n12p144

\begin{abstract}
Thinking quality is one of the important parts of the core competencies of English courses at senior high schools in China, indicating the cognitive ability and level of thinking in logical, critical, and innovative aspects. This study attempts to integrate the development of cognitive skills into reading instruction, showing how to immerse students with diverse learning activities in the teaching-learning process in terms of information acquisition, information processing, and information output. And their cognitive competencies at different levels are purposefully cultivated. Specifically, they are not only nurtured at the level of understanding factual information through observation and comparison but also facilitated for the deep understanding of the text through analysis, inference, and induction. Most importantly, they are encouraged to use their linguistic knowledge creatively with evaluative abilities, thus promoting the development of their English learning and thinking ability concurrently.
\end{abstract}

Keywords: thinking quality, EFL reading, instructional design

\section{Introduction}

Improving thinking quality is the key to the development of core competencies (Yan, 2016). The English Curriculum Standards for Senior High Schools developed by the Ministry of Education of the People's Republic of China in 2017, initially advocated thinking quality as one of the core competencies of teaching the English language, highlighting the importance of thinking quality in the development of core competencies. Thinking quality can help students enhance their ability to analyze and solve problems, observe and understand the world from a cross-cultural perspective, and make sound judgments on social matters and issues. (Ministry of Education of the PRC, 2018)

Teaching how to read is an important way to promote students' thinking quality (Lu, 2016). However, there is a phenomenon of "absence of critical thinking" (Huang, 1998) in reading instruction, mainly reflected in the following aspects: Teachers pay more attention to knowledge imparting, so a large number of learning activities are carried out with little room for thinking; Students tend to accept what is offered in class and they lack in-depth thinking about the reading materials. Therefore, this study takes the reading text What's in a name? as an example, aiming to integrate thinking ability training into the English reading process, so as to provide some reference to teaching practice.

\section{Literature Review}

\subsection{Thinking Quality Defined}

The word "thinking quality" originated from former Soviet literature. In the 1950s, former Soviet psychologists explained the connotation of thinking quality from the perspective of psychology. Smirnov (1957) believed that thinking is a reflection of reality. Thinking quality includes the breadth and depth of wisdom, the independence and flexibility of wisdom, and the order and agility of thought. Similarly, Bogoslovsky et al. (1979) pointed out that thinking quality is reflected in human intellectual activities and intellectual abilities, including the thirst for knowledge, the depth of thought, the flexibility of wisdom, logic, argument adequacy, etc. According to Petrovsky (1986), thinking quality refers to the independence and flexibility of thinking. It can be seen that the 
former Soviet psychologists not only emphasized the commonality of thinking development but also emphasized the personality of thinking development, indicating the relationship between thinking quality and cognitive activities. But they did not analyze thinking quality deeply.

Later, American psychologist Gilford (1991) defined the connotation of thinking quality from the perspective of children and adolescents. He believed that thinking quality refers to individuals' ability to show sensitivity, fluency, and flexibility when they face problems. In general, from the 1980s to the 1990s, researchers mainly understood thinking quality from the aspects of thinking ability and structure, believing that thinking quality refers to the personality characteristics of people's thinking, reflecting individual differences in intellectual or cognitive ability, mainly characterized by flexibility, agility, depth, criticality, and creativity (Lin, 2017). Criticality and creativity are basic characteristics of thinking, while flexibility, agility, and depth are the performance characteristics of thinking (Chen et al., 2019).

The connotation of thinking quality has been further enriched since 2000. Lin (2006) put forward the connotation of non-cognitive factors and non-intellectual factors of thinking quality, mainly including motivation, interest, emotion, will, temperament, and character. The English Curriculum Standards of China considers thinking quality as students' skills employed in the thinking process and the quality of their thinking in terms of logicality, criticality, and innovation (Ministry of Education of the PRC, 2018).

Many experts and scholars have different opinions and ideas on the concept of thinking quality, and it can be seen that thinking quality refers to the cognitive ability and levels in thinking activities, representing the cognitive aspects of core competencies and affecting people's understanding and judgments on things. It is believed that the development of thinking quality plays an important role in improving students' comprehensive skills. As such, it is of theoretical significance and practical value to conduct some research in this aspect.

\subsection{Researches on Thinking Quality in English Instruction}

Thinking Quality in English instruction has been a focus in education. Researchers stressed that thinking quality should be developed in a classroom environment at high schools (Hove, 2011; Narwianta, 2019). Teachers should create a constructive learning environment in which students can cooperate with others to solve relevant problems while encouraging them to think actively and creatively (Zhang and Kim, 2018). Zhu \& Zhu (2020) further suggested the communicative learning environment is conducive to the development of students' thinking ability. From the perspective of learning resources, Atiullah et al. (2019) found the instructional materials can improve students' critical thinking skills, broaden their thinking and imagination. They suggested that teachers should not only make full use of the English textbooks available but also make full use of the online resources. Atayeva1 et al. (2019) stated that using video clips is an effective way to cultivate learners' critical thinking in English teaching since technology is conducive to stimulating students' interest in learning and promoting them to think critically and creatively. From the perspective of the teaching process, Zhi \& Yan (2021) pointed out that logical questions should be designed to develop students' multiple thinking abilities. Similarly, Zhang (2015) and Liu \& Shi (2016) suggested that teachers should guide students with questions to interpret, analyze, and evaluate the information contained in the reading material and teachers should inspire students to compare and analyze Chinese and Western cultures so as to improve students' cultural sensitivity and appreciation.

In general, researches on thinking quality in English teaching mainly focus on the theoretical consideration of the development of thinking quality, especially in the aspect of critical thinking ability. Little attention has been paid to the in-depth discussions in English teaching practice and the cultivation of logical and innovative thinking, especially in the instructional design of EFL reading instruction. Therefore, it is of some significance to explore the instructional design of cultivating students' thinking quality in teaching English reading at senior high schools.

\section{Design Basis for English Reading Instruction}

\subsection{Basic Requirements from Curriculum Standard}

The requirements of the English Curriculum Standards in China for thinking quality are as follows: actively observe various linguistic and cultural phenomena, and distinguish important and less important information through comparison; objectively analyze the internal connections and differences among various information in different situations and contexts; discover differences, and infer the logical connections; summarize the common elements in various information obtained, construct new concepts, and interpret and deal with new problems and understand the world from new perspectives by way of inducing; raise critical questions about various viewpoints, analyze and value the viewpoints and thoughts, and form their own ideas (Ministry of Education of 
the PRC, 2018). As such, in reading class, students are required to enable to observe and analyze language and cultural phenomena in the reading material given, understand different historical and cultural elements.

\subsection{Teaching Content}

The reading material is selected from the fourth unit History and Tradition in the second book for senior high school English. This unit has eight interrelated sections, including introduction, listening and speaking, reading and thinking, grammar inquiry, reading, and writing. This reading section is about the British history and geographical overview, followed by cooperative language output through discussion and writing. Specific teaching content is reflected in three aspects. First, understand the formation and connotation of the name United Kingdom of Great Britain and Northern Ireland through the strategies such as prediction, analysis, and summary. Second, grasp the contributions made by four ethnic groups to Britain at various historical stages and use the language knowledge and the writing framework to generate writing content; Third, introduce Chinese cultural elements to foreign friends based on the reading content learned.

\subsection{Students Analysis}

The EFL students are in their first year at the senior high school, who have developed certain reading abilities. They can obtain and share information through observation, comparison, and analysis. However, they tend to use their existing experience to think in their mother tongue, which often causes limitations in understanding and writing in English. In terms of the content, they have some historical and cultural knowledge about England such as the origin of the British national name and the influence of the four races on the English language, but lack training in thinking skills.

\section{Instructional Design for English Reading}

According to Bloom's taxonomy of educational objectives and the concept of the English Curriculum Standards, this study designs a teaching process reflecting different thinking levels to promote students' language skills and thinking ability with various cognitive activities.

\subsection{Theoretical Basis: Bloom's Taxonomy of Educational Objectives and the Concept of the English Curriculum Standards}

According to Bloom's taxonomy of educational objectives, cognitive goals include six levels: memory, understanding, application, analysis, evaluation, and creation. Among them, memory, understanding, and application belong to low-order thinking, while analysis, evaluation, and creation belong to high-order thinking. (Anderson, 2008) Low-order thinking emphasizes the re-understanding of existing knowledge and the links established between prior and new knowledge, reflecting the process of information acquisition. High-order thinking emphasizes the judgment and formation of knowledge and the application of knowledge in new situations, reflecting the process of processing and producing information. Bloom's theory highlights the intrinsic link and the hierarchical progression between thinking levels, presenting the basic rules and characteristics of individuals' cognitive activities.

The English Curriculum Standards clearly stated thinking quality and classified it into four aspects: observation and comparison, analysis and inference, induction and construction, criticism and innovation. The order of the four aspects reflects the whole process of thinking, namely, information acquisition, information processing, and information output, which is consistent with Bloom's theory of cognition (Mei \&Wang, 2018). It is expected that students' thinking abilities can be improved with the training of thinking strategies at different levels of cognition.

\subsection{Instructional Objectives}

This lesson integrates the development of thinking quality into the whole process of teaching reading in English. The instructional objectives of this reading lesson are mainly reflected in four aspects: language ability, cultural awareness, study skills, and thinking quality. In the aspect of language ability, students will be able to accurately grasp the theme of history and tradition, properly use the vocabulary such as chief, legal, surround, military, defense, evidence, achievement, break away from, belonging to, etc., clarify the structure of the text, and infer the author's views and attitudes. In cultural awareness, students will be able to deepen their understanding of British historical and cultural traditions, master the historical background knowledge about the United Kingdom of Great Britain and Northern Ireland. In learning ability, students will be able to obtain the relevant information about geographic cultures from the map in the text to improve their ability of reading maps. In thinking quality, students will be able to summarize the main content of the text and put forward unique insights and opinions based on the reading passage; and they will be able to self-reflect and evaluate the content. The objectives of the four aspects are integrated. They are shown in the following table (Table 1). 
Table 1. Instructional objectives

\begin{tabular}{ll}
\hline Reading instructional objectives & cognitive levels \\
\hline Extract specific geographic and cultural information according to map hints. & Observation and comparison \\
Clarify the text structure and infer the author's main viewpoints and & \\
paragraph theme sentences through text analysis. & Analysis and inference \\
Understand the long and complex formation process of the United Kingdom & \\
of Great Britain and Northern Ireland. & \\
$\begin{array}{l}\text { Summarize the contributions the four major ethnic groups (ancient Romans, } \\
\text { Saxons, Vikings, Normans). }\end{array}$ & \\
$\begin{array}{l}\text { Generalize the history and cultural characteristics of British and put forward } \\
\text { unique insights and views. }\end{array}$ & Induction and inference \\
Provide a tip for foreigners' visit in China based on panel discussions. \\
Write a letter based the knowledge in the discourse.
\end{tabular}

\subsection{Teaching Procedure}

In the teaching procedure, the attention is paid to the students' language learning and cognitive development. High-density thinking training is integrated into the whole teaching process, enabling students to be in a positive and active learning state, and then carry out a series of thinking activities such as discussion and questioning, cooperation and interaction, presentation and reflection. Specifically, guide students to understand the text content to cultivate their logical thinking ability, evaluate the text meaning to develop their consciousness for critical thinking, and expand the text content to improve their language ability. The teaching procedure reflects the cultivation of different thinking levels. As shown in Figure 1, the tasks are designed following the process of "learning and understanding", "applying and practicing", and "transferring and creating" advocated by the new curriculum standard.

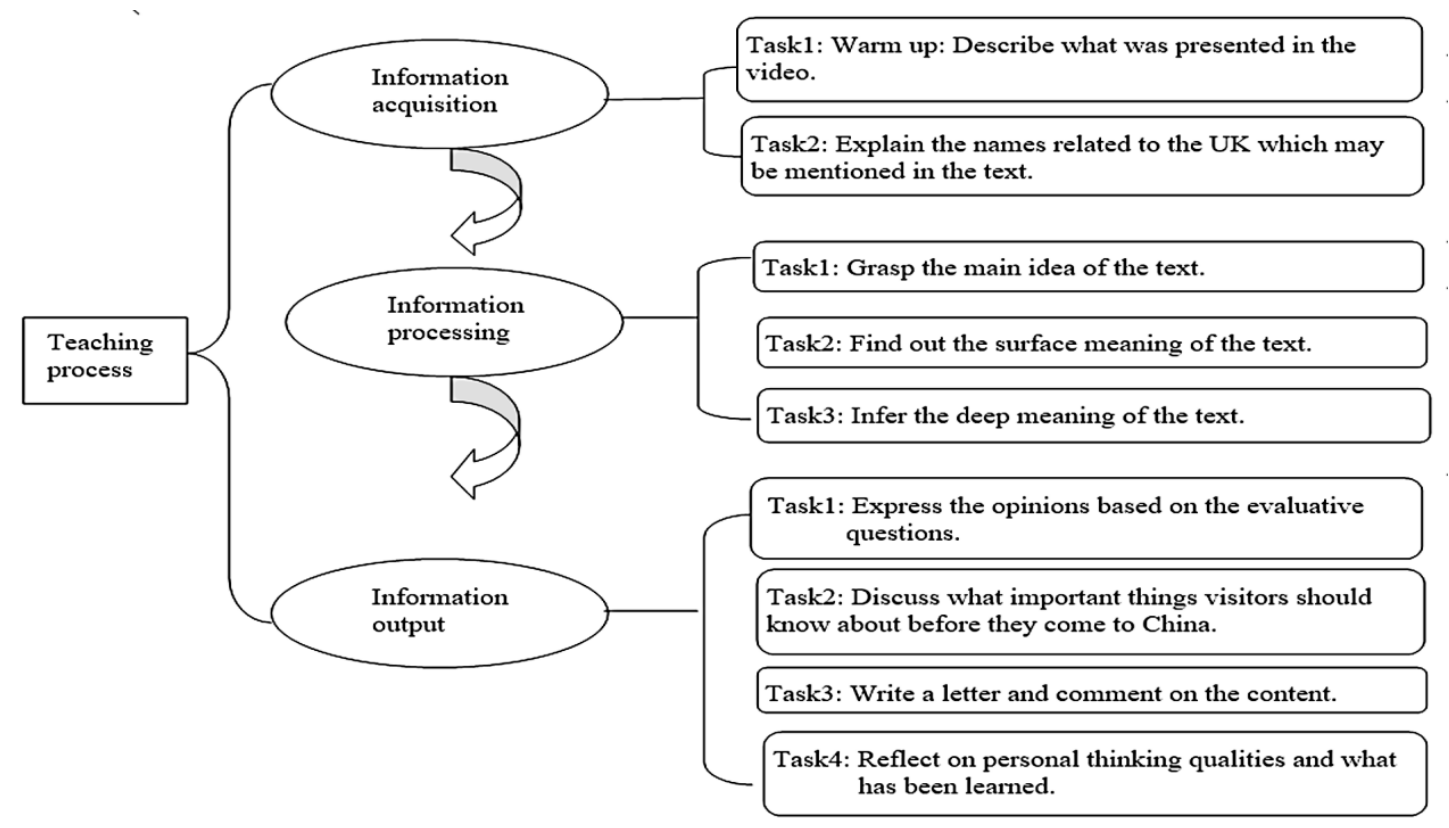

Figure 1. The flow chart of teaching process

4.3.1 Information Acquisition: to Promote the Development of Students' Logical Thinking Ability through the Cognitive Activities of Identification

Information acquisition refers to obtaining the original information in a given source. Reading is an intellectual activity in which students have to understand passages with the help of visual aids. Observation is an important way for students to obtain rich perceptual materials and it is also the basis to develop various thinking abilities. In the part, visual materials are used to improve students' intuitive perception and activate their discriminative cognition. There are two specific tasks: 
Task 1: Watch a video of the British national anthem God Save the Queen and describe its contents. British.

Task 2: Use a mind map (Figure 2) to preliminarily understand the connotation of different names of

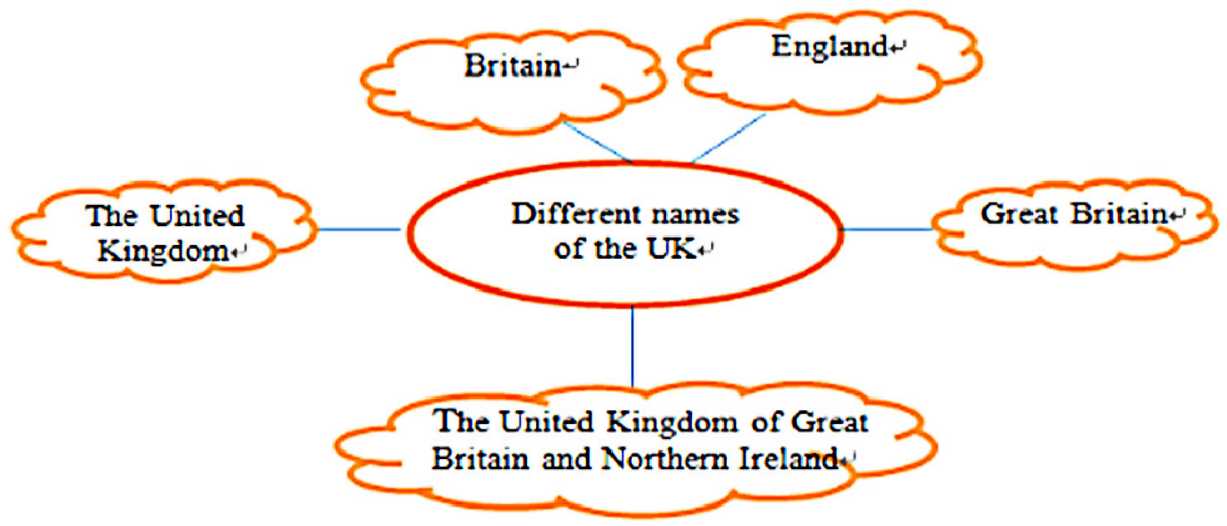

Figure 2. Different Names of Britain

Classroom introduction, as the foreshadowing stage of the teaching process, plays an important role in creating a harmonious learning atmosphere to arouse students' interest in learning. Video input is used for this purpose. The theme and the map in the text are used to enhance students' inference ability. Similarly, the mind map is used to present different British names to deepen students' understanding of the background information of British names, and to promote students to actively think about the literal and implicit meanings of the title.

\subsubsection{Information Processing: to Develop Students' Logical Thinking Ability with Cognitive Activities}

Information processing is an important part of the teaching process. It is a process of screening and classifying original information, which helps students to grasp the theme of the text as a whole. In this section, students are guided to focus on the connotation of the text and make reasonable judgments through cognitive activities such as comparison, synthesis, and induction, so that they can grasp the structure of the text, paying attention to the explicit information of text in details such as British culture and tradition.

Task 1: Analyze the text content and grasp the text structure

The focus of text analysis is to initiate students' logical reasoning ability. Through three subtasks, students are guided to analyze the material with a better understanding. Besides, the mind map (Figure 2) is used to assist students to analyze the structure of the text and refine the main views so as to improve the ability to understand the meaning of the text.

(1) Generalize the topic sentence of each paragraph.

(2) Analyze the structure of the passage.

(3) Summarize the main ideas of Part 1 and Part 2 respectively.

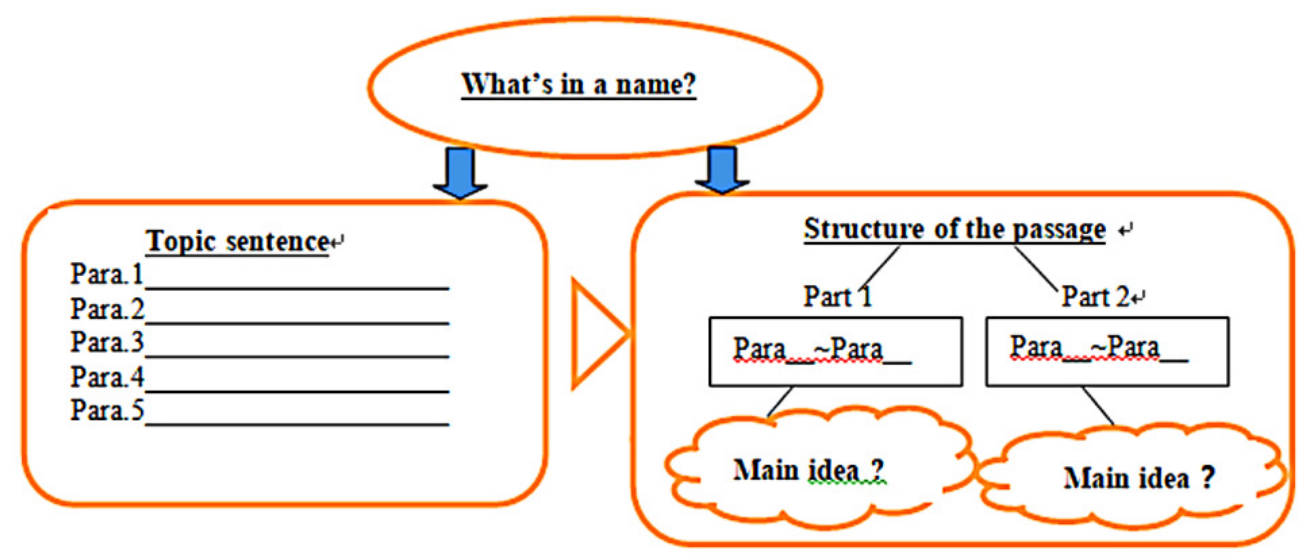

Figure 3. The frame diagram of the text 
Task 2: Preliminarily understand the text and extract the explicit information of the text.

Three basic questions are designed to guide students to understand the text holistically to facilitate students' cognitive ability of information understanding and extraction.

(1) When did "the United Kingdom of Great Britain and Northern Ireland" form?

(2) Which country was joined to the Kingdom of England first?

(3) How was "the United Kingdom of Great Britain and Northern Ireland" formed?

Task 3: Deeply understand the text and infer its deep meaning.

Inferring the deep meaning of the text means that students can understand the text meaning and the causal relationship between facts, understand the author's attitude with the explicit information available. The main purpose of this task is to stimulate students to develop their ability of information inference with open-ended questions.

(1) Why is each part of the UK called "a country"?

(2) Why is the UK worth visiting?

(3) Why does the author mention London?

Information processing in reading mainly involves learning about the text content, understanding the author's ideas based on the context and background information of the reading material. Through an in-depth analysis of the text, students can grasp the logical connection of relevant information, ideological connotation, and spiritual essence so as to improve their logical thinking ability.

4.3.3 Information Output: to Develop Students' Ability to Think Deeply through Task-Based Opinion Expression and Language Output

Information output is the key link in the teaching process, which can not only train students' language ability but also strengthen their thinking ability. The following tasks based on reading discourse can stimulate students to solve problems creatively. Students can be encouraged to use the language they have learned to show their views, evaluate the values of the text, and enhance their ability to transfer knowledge to new situations.

Task 1: Present your opinions combined with personal experience.

Students express their views in combination with their personal experience to further internalize the language knowledge they have learned. This task aims to develop students' critical thinking through three questions. Specifically, Students are initiated to explore the contributions that the four ethnic groups made in the different historical stages, the best way to experience the British traditional culture, and evaluate the author's view.

(1) What do you think of the contributions that four ethnic groups made to the UK? Why?

(2) What do you think of the best way to experience the traditions in the UK? Why?

(3) Do you agree with the author's opinion that we should learn about a country through its history? Why or why not?

Task 2: Discuss the topic of foreign friends' visits to China and provide suggestions for their coming.

Discussions are conducive to students' positive thinking and exploration, helping students break through the limitations of their own thinking and jointly solve a problem with collective wisdom. Students discuss the preparation foreigners should make before visiting China in groups. On the one hand, students try to express the cultural content with the language they have learned with brainstorming activity so as to have a deeper understanding of Chinese culture; on the other hand, students have to provide more valuable suggestions for foreign visitors with helpful information.

Task 3: Carry out extended writing and mutual evaluation.

Expanded writing can help students deepen their understanding of the reading material and improve their innovative thinking skills. In the task, students are required to introduce the historical background of a place in China they recommend to foreign friends according to the framework of letter writing (Table3). Then, students are required to evaluate their writing in terms of vocabulary, grammar, and structure as well as their mechanical skills. 


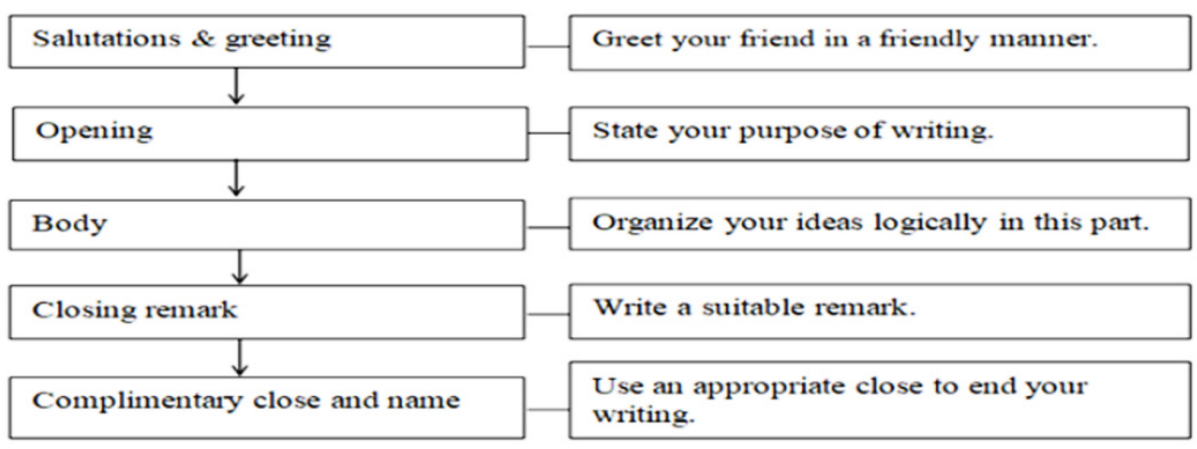

Figure 4. The framework for a letter writing

The above three tasks focus on improving students' profound thinking ability. Through these three tasks, teachers encourage students to objectively analyze and evaluate the text content from multiple perspectives to form their independent views; complete writing independently based on the letter-writing framework; evaluate and revise peers' writing in order to develop their ability of deep thinking.

Task 4: Self-reflection and evaluation

Reflection and evaluation refer to the value judgment and comprehensive evaluation of certain facts, phenomena, and opinions through critical thinking (Markman \& McMullen, 2003). Students are required to reflect on the learning content and make corresponding judgments to enhance their self-awareness and ability of deep thinking. In the part, students are guided to finish two sub-tasks. Firstly, evaluate the development of thinking quality according to the evaluation table (Table 2), and reflect on the contents of "partially achieved" and "completely unachieved" to enhance their abilities of self-awareness and self-monitoring.

(1) Reflect on personal thinking qualities based on the evaluation table of thinking quality.

Table 2. Evaluation Table of Thinking Quality

\begin{tabular}{|c|c|c|c|c|}
\hline \multirow[t]{2}{*}{ Thinking quality } & & \multicolumn{3}{|c|}{ Self-assessment } \\
\hline & & $\begin{array}{l}\text { Completely } \\
\text { achieved }\end{array}$ & $\begin{array}{l}\text { Partly } \\
\text { achieved }\end{array}$ & $\begin{array}{l}\text { Completely } \\
\text { unachieved }\end{array}$ \\
\hline \multirow{5}{*}{ Logical thinking } & $\begin{array}{l}\text { When reading, I could pay attention to the } \\
\text { key sentences of each paragraph. }\end{array}$ & & & \\
\hline & $\begin{array}{l}\text { While reading, I could make a structural } \\
\text { division of this text. }\end{array}$ & & & \\
\hline & $\begin{array}{l}\text { I could guess the content of the text from } \\
\text { the title. }\end{array}$ & & & \\
\hline & $\begin{array}{l}\text { I could carefully ponder the place names in } \\
\text { the text and compare their similarities and } \\
\text { differences. }\end{array}$ & & & \\
\hline & $\begin{array}{l}\text { I could find out the supporting basis to } \\
\text { verify my views. }\end{array}$ & & & \\
\hline \multirow[t]{4}{*}{ Critical thinking } & $\begin{array}{l}\text { I was good at finding out the author's } \\
\text { implicit views. }\end{array}$ & & & \\
\hline & $\begin{array}{l}\text { After reading, I could evaluate the text } \\
\text { from many aspects. }\end{array}$ & & & \\
\hline & I could ask some novel questions. & & & \\
\hline & $\begin{array}{l}\text { While reading, I could imagine myself as } \\
\text { one of the four British races mentioned in } \\
\text { the text. }\end{array}$ & & & \\
\hline $\begin{array}{l}\text { Innovative } \\
\text { thinking }\end{array}$ & $\begin{array}{l}\text { After reading, I could do some extended } \\
\text { writing based on the reading passage. }\end{array}$ & & & \\
\hline
\end{tabular}


Secondly, students are guided to reflect on the learning content, find out the points they haven't grasped, and think about improvement strategies for deep learning.

(2) Reflect on what has been learned with a mind map.

Mind mapping can make knowledge visible and visualized, which facilitates learners to sort out their thoughts and types of knowledge. In the second sub-task, students are guided to use a mind map to conduct an in-depth analysis and reflection on the text content, so as to grasp the logical links of knowledge, systematically organize the knowledge they have learned, and make a general summary and evaluation of their learning.

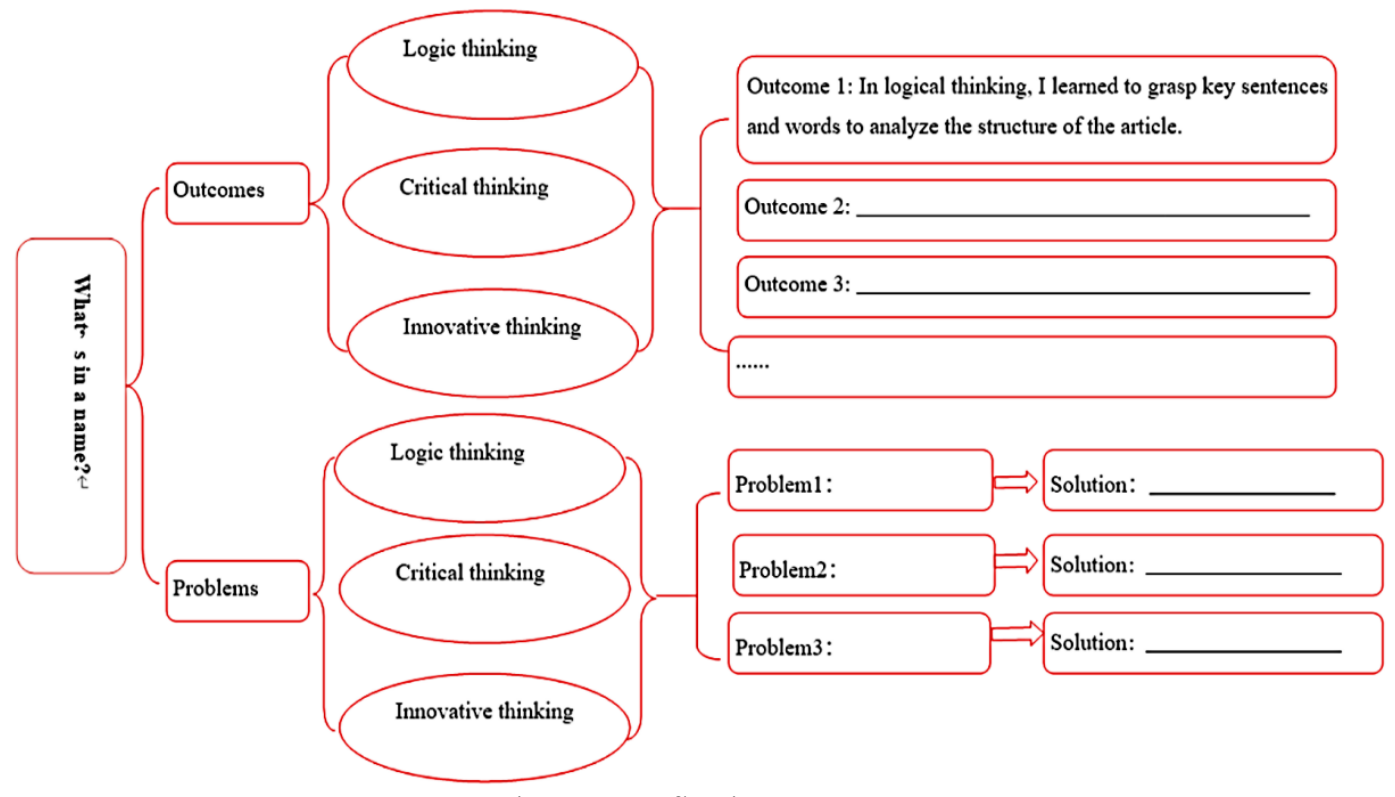

Figure 5. Reflection content

Self-evaluation and reflection are important ways to optimize students' learning effects and improve students' thinking ability. Task 4 is designed to stimulate students' cognitive drive, mobilize students' cognitive strategies, and finally promote them to develop sound thinking quality.

\section{Implication and Conclusion}

\subsection{Implication}

Through the process of information acquisition, information processing, and information output, the development of thinking quality is integrated into the teaching tasks of different thinking levels to promote the coordinated development of students' English learning and thinking ability. It should be pointed out that the development of language ability and thinking ability are interdependent and mutually reinforcing. Therefore, educational practitioners should pay attention to the following aspects.

First, the instructional design from the perspective of thinking quality is not to ignore the learning and construction of language knowledge, but to help students form the habit and ability of deep thinking in the process of reading. In other words, the development of thinking quality needs to be combined with language learning, transformed into an observable explicit expression with the help of specific learning tasks, and integrated into the process of understanding the text content, mastering the linguistic knowledge.

Second, the development of thinking quality cannot be achieved overnight, and it needs to experience a diversified learning process. Students learn to think in the process of learning and internalize and use the knowledge learned in new situations. In fact, both "language learning and language use" and "cultural understanding and appreciation" are inseparable from the development of thinking in the cognitive process (Li \& Zheng, 2018; Zhang \& Ma, 2021). Therefore, English teaching should combine language learning with the development of thinking. In the teaching objectives, the levels of thinking quality should be fully reflected, and the students' thinking consciousness should be trained purposefully, so that they can gradually learn to use multiple arguments to prove their own views and their target language, finally developing a strong critical ability.

Third, the evaluation on thinking quality should reflect the development orientation. It is more suitable to stimulate students to dialectically view problems through real tasks and open questions, and observe whether 
students can flexibly use subject knowledge. In other words, we should focus on students' performance of using the knowledge they have learned to solve practical problems rather than selecting optional answers to recognition type of exercise or activities.

\subsection{Limitations and Future Research Directions}

There are some limitations in the study that should be mentioned. First, the proposed teaching process was conducted only in an instructional design for one English reading lesson, so the generalizability of the findings may be limited. Further instructional designs for more English reading lessons for different grades are needed since thinking qualities are dynamic in nature and students vary in their ways of thinking with the development of their cognition and experience Thus, a longitudinal way of thinking quality studies could be conducted. In addition, this study explored the preset teaching process of integrating thinking quality and language ability without verifying the effect of the instructional design. More empirical studies should be done in evaluating the effectiveness of this type of instructional design in future studies.

\section{Acknowledgements}

The research was supported by grants from the National Social Science Fund, China for "Research on the implementation status and countermeasures of language education policy in Hong Kong" (Grant number: BEA180110).

\section{References}

Anderson, L. W., \& Krathwohl, D. R. (2001). A Taxonomy for Learning, Teaching, and Assessing: A Revision of Bloom's Taxonomy of Educational Objectives. London: Longman.

Atayeva1, M., Ciptaningrum, D. S., Hidayah1, R., Kassymova, G. K., Dossayeva, S. K., \& Akmal, A. (2019). Cultivating Junior High School Students' Critical Thinking Skills by Using a Short-video in English classroom. Bulletin the National academy of sciences of the Republic of Kazakhstan, 5, 57-69. https://doi.org/10.32014/2019.2518-1467.124

Atiullah, K., Fitriati, S. W., \& Rukmini, D. (2019). Using Revised Bloom's Taxonomy to Evaluate Higher Order Thinking Skills (Hots) in Reading Comprehension Questions of English Textbook for Year X of High School. English Education Journal, 9(4), 428-436. Retrieved from https://journal.unnes.ac.id/sju/index.php/eej

Bogoslowski. (1979). General Psychology. Beijing: People's Education Press, 196.

Chen, Z., Wang, Q., \& Qian, X. (2019). Thinking Quality and Its Development Ways in the Core Literacy of English Discipline. Curriculum, Teaching material, Teaching method, 1, 91-98.

Gilfort. (1991). Creative talent-their nature, purpose and cultivation. Shi Liangfang et al. Translating. Beijing: People's Education Publishing House, 1991.

Huang Y. S. (1998). Absence of critical thinking. Foreign Languages and Teaching, (1), 1-9.

Li, Y., \& Zheng, G. (2018). Classroom teaching reform in primary and secondary schools from the perspective of core literacy. Educational research, 2, 80-87.

Lin, C. (2006). A Review of Thinking Psychology Research. Journal of Beijing Normal University (Social Sciences Edition), 5, 35-42.

Lin, C. (2017). Learning and Development (4th ed.): Psychological Ability Development and Training of Primary and Middle School Students. Beijing: Beijing Normal University Press, 159.

Liu, S., \& Shi, Y. (2016). The Application of Critical Reading Strategy in High School English Reading Teaching. Education and Scientific Research in Shanghai, 10, 68-71.

Lu, Z. (2016). The connotation and possibility of promoting thinking quality development. English teacher, 5, 6-12.

Markman, K. D., \& McMullen, M. N. (2003). A Reflection and Evaluation Model of Comparative Thinking. $\begin{array}{lllll}\text { Personality and Social Psychology } & \text { Review, } & 7(3), & \text { 244-267. }\end{array}$ https://doi.org/10.1207/S15327957PSPR0703_04

Mei Deming, \& Wang Qiang. (2018). Interpretation of English Curriculum Standards for Senior High Schools (2017 ed.). Beijing: Higher Education Press (p. 72).

Ministry of Education of the People's Republic of China. (2018). General Senior High School Curriculum Standards English (2017 ed.). Beijing: People's Education Press. 
Narwianta, N., Linggar Bharati, D, A., \& Rukmini, D. (2019). The Evaluation of Higher Order Thinking Skills in English School Nationally Standardized Examination at State Senior High School 6 Semarang. English Education Journal, 9(3), 316-32. Retrieved from https://journal.unnes.ac.id/sju/index.php/eej

Petrosky. (1986). General Psychology. Gong Haoran et al. Translating. Beijing: People's Education Press, 388.

Smirnov. (1957). Psychology. Zhu Zhixian et al. Translating. Beijing: People's Education Press, 301.

YanYang. (2016). Developing core literacy: improving thinking quality is the key [EB/OL]. (2016 - 05-11) [2020-11-10]. Retrieved from https://jysb.shuren100.com/2016-05/11/content_49850.html

Zhang, A. (2015). How to Develop Students in High School English Teaching. Beijing Education, 9, 42-43.

Zhang, C., \& Ma, R. (2021). The effect of textual glosses on L2 vocabulary acquisition: A meta-analysis. Language Teaching Research, 1, 1-20. https://doi.org/10.1177/13621688211011511

Zhang, L., \& Kim, S. (2018). Critical Thinking Cultivation in Chinese College English Classes. English Language Teaching, 11, 1-6. https://doi.org/10.5539/elt.v11n8p1

Zhi, Y., \& Yan, X. (2021). Research on the Cultivation of Multiple Thinking Ability in Senior High School English Teaching. Journal of Frontiers in Educational Research, 1(6), 107-111.

Zhu, Z., \& Zhu, X. (2020). The Teaching Design of Senior High English Reading Class Based on Cultivation of Thinking Quality. International Journal of New Developments in Education, 2(7), 20-25.

\section{Copyrights}

Copyright for this article is retained by the author(s), with first publication rights granted to the journal.

This is an open-access article distributed under the terms and conditions of the Creative Commons Attribution license (http://creativecommons.org/licenses/by/4.0/). 